\title{
Australian Mental Health Care Practitioners' Cultural Competence, Therapeutic Alliance, Desirable Responding and Racial/Ethnic Attitudes
}

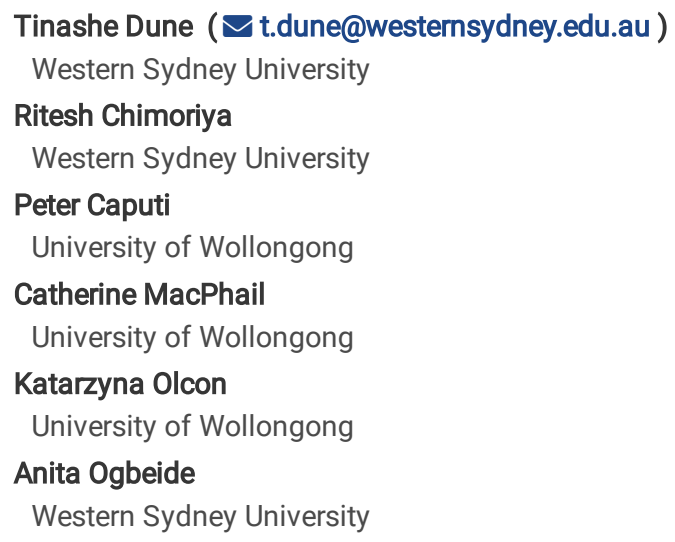




\section{Abstract \\ Background}

Racial, ethnic, religious, and cultural diversity in Australia is rapidly increasing. Although Indigenous Australians account for only approximately $3.5 \%$ of the country's population, over $50 \%$ of Australians were born overseas or have at least one migrant parent. Migration accounts for over $60 \%$ of Australia's population growth, with migration from Asia, Sub-Saharan African and the Americas increasing by $500 \%$ in the last decade. Little is known about Australian mental health care practitioners' attitudes toward this diversity and their level of cultural competence.

\section{Aim}

Given the relationship between practitioner cultural competence and an effective therapeutic alliance with diverse clients, this study aimed to identify factors that influence non-White and White practitioner cultural competence and therapeutic alliance.

\section{Methods}

An online questionnaire was completed by 139 Australian mental health practitioners. The measures included: the Multicultural Counselling Inventory (MCI); the Color-blind Racial Attitudes Scale (CoBRAS); and the Balanced Inventory of Desirable Responding (BIDR). Descriptive statistics were used to summarise participants' demographic characteristics. One-way ANOVA and Kruskal-Wallis tests were conducted to identify between-group differences (non-White compared to White practitioners) in cultural competence, therapeutic alliance, and racial and ethnic blindness. Correlation analyses were conducted to determine the effect of participants' gender or age on cultural competence and therapeutic alliance. Hierarchical multiple regression analyses were conducted to predict cultural competence and therapeutic alliance.

\section{Results}

The study demonstrates that higher $\mathrm{MCl}$ total scores (measuring cultural competence and therapeutic alliance) were associated with being non-White, older age, greater attendance of cultural competence-related trainings and increased awareness of general and pervasive racial and/or ethnic discrimination. Practitioners with higher $\mathrm{MCl}$ total scores were also likely to have higher self-deceptive positive enhancement scores on the BIDR than those with lower $\mathrm{MCl}$ total scores.

\section{Conclusion}

The findings highlight that the current one-size-fits-all and skills-development approach to cultural competence training ignores the significant role that practitioner diversity and differences play in the therapeutic alliance. The recommendations from this study can inform clinical educators and supervisors about the importance of continuing professional development relevant to practitioners' age, racial/ethnic background and professional experience.

\section{Background}

Australia is increasingly known for its diversity and multiculturalism. By June 2020, there were over 7.6 million migrants living in Australia, $29.8 \%$ of Australia's population were born overseas and Australia's population increased by 194,400 people due to net overseas migration (1). This is in addition to Australia's 798,400 Aboriginal and Torres Strait Islander people, which was a 19\% increase between 2011 and 2016 (2). While the region of largest immigration remains the United Kingdom, migration from Asia, Sub-Saharan Africa and the Americas has increased by $500 \%$ in the last 10 years (2). Sixty percent of migrants, who can demonstrate high levels of English proficiency, educational attainment, and financial independence, arrive to Australia on skilled worker and/or study visas with an additional $30 \%$ arriving as partners or family to these migrants. Australia also has a humanitarian visa program which accounts for less than $10 \%$ of Australian migration and includes asylum seekers who may have limited English, education, and access to financial support (2). This level of diversity requires the Australian society as well as its systems, services, and support providers to consistently adapt to meet the needs of a rapidly changing population.

However, despite increased diversity, Australian society and all its systems continue to operate within the framework of Whiteness $(4,5)$. Whiteness is a colonial and post-colonial ideology and a power structure characterised by racial dichotomies and ethnic hierarchies. In W.E.B. Du Bois' 1920 essay, The Souls of White Folk $(6,7)$, he described supremacy and entitlement within Whiteness:

But what on earth is whiteness that one should so desire it? Then always, somehow, someway, I am given to understand that whiteness is the ownership of the earth, forever and ever, Amen! (p. 16)

DiAngelo (8) explains that "Whiteness itself refers to the specific dimensions of racism that serve to elevate White people over people of color" (p. 56). As such, other scholars indicate that Whiteness leads Whites to believe themselves to be the "predestined master[s] of the world" (9). These definitions 
of Whiteness clarify who reaps benefits from Whiteness and those who do not. Hence, in this paper, the term non-White refers to individuals who are excluded from being beneficiaries of Whiteness as a result of their racial, ethnic, cultural, religious, linguistic, or national identities (10).

We recognise that not all Whites encounter the same privileges or to similar levels, or that Whiteness has maintained the same parameters over time, or that it is impermeable and inflexible $(11,12)$. Additionally, we recognise that Whiteness (and how those who benefit, or are excluded, from it are defined) is constantly under revision (13). Even within this consistent state of flux, Whiteness and its consequences endure (14) and are present across all areas of Western (if not global) environments, systems, and practices (15).

One such system is the mental health care system. Mental health is a core element of human health and wellbeing. In 2020 , the Australian Institute of Health and Welfare (AlHW) (16) indicated that $45 \%$ of all Australians aged 16 to 85 years -8.7 million people - will experience mental illness at some point in their life. According to 2015 statistics, mental illness and substance misuse were the second largest contributor (23\%) of the non-fatal burden of disease in Australia (17). During the 2017 and 2018 financial year, \$9.9 billion (16) was spent on mental health, with spending increasing in 20182019 to $\$ 10.6$ billion (18). Given the prevalence and social and economic costs of mental illness, access to and effectiveness of mental health services is crucial. Mental health is therefore an area in which systems and practitioners need to adapt and demonstrate flexibility to support clients (19).

However, health practitioners and systems struggle to adapt or to be flexible when working with clients who do not fit within rigid frameworks of Whiteness in health care $(4,5)$. Importantly, the negative health outcomes and experiences of non-Whites within (mental) health care settings are well documented and related to systems and practitioners that harbor constructions of health and wellbeing based on frameworks of Whiteness (20-23). For instance, findings from our systematic review, representing 5,870 mental health care practitioner constructions of non-White people, indicate that practitioners who perceived non-White people as having 'backwards beliefs' about mental health were less likely to engage in culturally competent health care approaches while working with non-White people (20). It is therefore important to consider and identify Australian mental health practitioners' attitudes to Whiteness and their impact on cultural competence and the therapeutic alliance. In doing so, advances can be made in practitioner training and clients' mental health outcomes.

In Australia, little is known regarding mental health workers' cultural competence or attitudes towards non-White people and how these factors influence the therapeutic alliance. Contemporary understandings of health care provider attitudes can be implied from well documented negative health experiences and outcomes within minority populations and across variety of health care settings (24). Overall, the crux of these experiences are linked to health systems and providers internalising Anglo-centric and racist constructions of health and wellbeing (25). As a solution, practitioners and researchers advocate for anti-racism and improved cultural competency (15). Cultural competency is defined as "a set of congruent behaviours, attitudes and policies that come together in a system, agency or among professionals and enable that system, agency or those professionals to work effectively in cross-cultural situations" (27). International evidence indicates that when practitioners internalise and enact the principles of cultural competence, they are able to cultivate and maintain a positive therapeutic alliance between themselves and their clients (15, 28-30).

Therapeutic alliance is broadly defined as "the collaborative and affective bond between therapist and patient ... [and] is an essential element of the therapeutic process" (31). The therapeutic alliance is exemplified by bi-directional and mutual collaborations between mental health care providers and clients, are dependent on a person-centred health care ethos (32) and based on a mutually nurtured psycho-socio-emotional connection (33). With, the concept of the therapeutic alliance has its origins in early psychoanalytic theories (e.g., 34) and is now a staple of contemporary evaluations and conceptualisations of the therapeutic process. Notably, international evidence indicates that the therapeutic alliance is strongly associated with clients' mental health engagement and outcomes $(31,35)$.

Given the limited literature on the topic specific to the Australian context this study aimed to identify the factors that influence practitioner constructions of non-White people and their relationship to practitioners' perceived cultural competence and therapeutic alliance. We therefore asked the following research questions:

1. How culturally competent are Australian mental health care practitioners?

2. How does cultural competence relate to practitioner therapeutic alliance with non-White people?

3. What demographic (age, sex, gender, ethnicity) and mutable variables (experience with non-White clients, attendance at cultural competence training) predict cultural competence and therapeutic alliance?

4. How are practitioner constructions of non-White people associated with cultural competence and the therapeutic alliance?

\section{Methods}

This quantitative study is part of a larger body of work using a sequential mixed methods design (see publications 11, 12, 20). The current study used a cross-sectional design with non-probability sampling and validated survey measures.

\section{Recruitment and Participants}

Participants included individuals aged 18 years and over, living in Australia and self-identifying as a mental health care practitioner or trainee. Participants were recruited via distribution of advertising to the Australian Psychological Society and the Australian Clinical Psychologists Association. 
Additional recruitment took place via social media including Facebook, Twitter, Instagram, and Linkedln. Participants were invited to complete the survey online or request a paper copy.

One hundred and eighty-two practitioners commenced the survey. The majority engaged in the survey online $(n=175)$ while seven completed the survey in hardcopy. After screening for completeness of all the demographic, MCl, CoBRAS and BIDR items, 139 participants remained. The study was approved by and conducted within the guidelines of the Human Research Ethics Committee (Approval Number 2017/105) at the University of Wollongong.

\section{Quantitative Survey Measures}

The survey included the following measures:

\section{Demographic Questionnaire}

The demographic questions collected information about participants' age, gender, ethnicity and country of origin, highest degree achieved, year highest degree achieved, mode of professional practice/training (private and/or public), years of experience and engagement with post-qualification cultural competency training. Participants were also asked where they completed or are engaged in their psychology/counselling training and how many nonWhite clients they see in a month.

\section{Multicultural Counselling Inventory ( $\mathrm{MCl}$ )}

This 40-item self-report inventory (36) assesses behaviours and attitudes related to four multicultural competencies on a 4-point Likert scale from very inaccurate (1) to very accurate (4). For each item, a score of 1 indicates low multicultural competence and a score of 4 indicates high multicultural competence (37). Scale scores are obtained by adding the items specific to each subscale. The $\mathrm{MCl}$ total score ranges from 40 to 160 with higher scores indicating greater multicultural competence. Higher subscale scores also indicate greater multicultural competence in the respective subscale areas (see below). As explained in Ottavi et al. (38), the four areas of multicultural competency are as follows:

1. Skills-11 items measuring general counselling and specific multicultural counselling skills. Sample items include "When working with all clients, I am able to be concise and to the point when reflecting, clarifying, and probing" and "When working with minority clients, I monitor and correct my defensiveness." Minimum score = 11, maximum score $=44$.

2. Knowledge-11 items measuring treatment planning, case conceptualization, and multicultural counselling research. Sample items include "When working with minority clients, I keep in mind research findings about minority clients' preferences in counselling" and "When working with minority clients, I apply the socio-political history of the clients' respective minority groups to understand them better." Minimum score $=11$, maximum score $=$ 44.

3. Awareness-10 items measuring multicultural sensitivity, interactions, and advocacy in general life experiences and professional activities. Sample items include "I am involved in advocacy efforts against institutional barriers in mental health services for minority clients" and "When working with international students or immigrants, I understand the importance of legalities of visa, passport, green card and naturalization." Minimum score $=10$, maximum score $=40$.

These three subscales allowed us to measure cultural competence in line with similar principles in the cultural competence model developed by Campinha-Bacote (39).

4. Relationship-8 items measuring the counsellor's interaction process with the minority client (e.g., comfort level, worldview, and counsellor's trustworthiness). Sample items include "When working with minority individuals, I am confident that my conceptualization of individual problems do not consist of stereotypes and biases" and "When working with minority clients, I perceive that my race causes the client to mistrust me." Minimum score $=8$, maximum score $=32$.

We used this subscale to measure therapeutic alliance in line with principles of this concept as outlined in Escudero, Friedlander (40).

Internal consistency reliabilities (Cronbach's alphas) reported by Sodowsky, Taffe (36) were 0.80 for Multicultural Awareness, 0.80 for Multicultural Counselling Knowledge, 0.81 for Multicultural Counselling Skills, 0.67 for Multicultural Counselling Relationship, and 0.86 for the full scale. Our study reports 0.78 for Multicultural Awareness, 0.83 for Multicultural Counselling Knowledge, 0.87 for Multicultural Counselling Skills, 0.69 for Multicultural Counselling Relationship, and 0.90 for the full scale.

\section{Color-Blind Racial Attitudes Scale (CoBRAS)}


This study used an adapted version of the Color-Blind Racial Attitudes Scale (41) to assess practitioners' constructions of non-White people. The CoBRAS consists of 20 items to assess attitudes with a 6-point Likert scale of 1 (strongly disagree) to 6 (strongly agree). The CoBRAS is designed to assess cognitive dimensions of colour-blind racial attitudes including the degree to which respondents distort, deny, and/or minimize the existence of institutional racism (e.g., "Everyone who works hard, no matter what race they are, has an equal chance to become rich," and "Racism may have been a problem in the past, but it is not an important problem today"). Total scores can range from 20 to 120, with higher scores representing greater colourblind racial beliefs (41) which are an indication of greater levels of unawareness or blindness to the existence and impact of Whiteness on people and systems.

The CoBRAS assesses blindness in three areas: Racial \& Ethnic Privileges, Institutional Discrimination, and Blatant Racial \& Ethnic Issues. The Racial \& Ethnic Privilege subscale measures blindness to the existence of privileges attributed to Anglo-Australians. The Institutional Discrimination subscale measures limited awareness of the implications of institutional discrimination and exclusion. The Blatant Racial and Ethnic Issues subscale measures unawareness of general and pervasive racial/ethnic discrimination.

Although the CoBRAS is based on the U.S. context and uses terminology relevant to racial dynamics in the U.S., many of these dynamics (e.g., institutional racism and systemic discrimination) are also present within the Australian context. As such, the content of the items did not require amendment, however their context 'American' versus 'Australian' or 'United States' versus 'Australia' or 'African American' versus 'Afro-Australian' did require revision. In place of the term 'White' the term 'Anglo-Australian' was used as many individuals who identify as being of an ethnic minority may appear White but may experience prejudice or discrimination due to other manifestations of their ethnicity (wearing a hijab, having a non-Australian accent, or having non-Anglo family members for example). Finally, for those items which only mention race, and not race and ethnicity, the word ethnicity or ethnic has been added to reflect the realities of multiculturalism in Australia where ethnicity may be mutually exclusive of race (e.g., "Racial problems in the U.S. are rare, isolated situations" was changed to "Racial problems in Australia. are rare, isolated situations". American spellings (e.g., color versus colour) were also amended in line with Australian spelling conventions.

Neville et al. (41) reported that the coefficient alpha for the total CoBRAS was 0.91. Our study demonstrates the coefficient alpha for the total CoBRAS was 0.87, Factor: Unawareness of Racial Privilege was 0.78, Factor: Unawareness of Institutional Discrimination was 0.71 , and Factor: Unawareness of Blatant Racism Issues was 0.71 .

\section{Balanced Inventory of Desirable Responding}

The Balanced Inventory of Desirable Responding (BIDR) (42) measures the tendency to respond and exhibit behaviours or thoughts that are viewed as socially desirable but are not accurate representations of an individual's real attitudes (43). Scholars in counselling have used BIDR to control counsellors' social desirability in their self-report data (44). Sample items include "My first impressions of people usually turn out to be right" and "I always know why I like things." BIDR consists of 40 items with two subscales of 20 items each evaluating impression management and selfdeception. The scale is composed of a response format consisting of a 7-point Likert scale ranging from 1 (not true) to 7 (very true); 1 point is scored for each extreme answer ( 6 or 7 ) with a total score ranging from 0 to 40 . Higher scores indicate a greater tendency to respond and exhibit behaviours or thoughts that are viewed as socially desirable. BIDR has been used successfully with various racial/ethnic and cultural groups (44). Chao (45) reported a coefficient alpha of 0.85 with a sample of graduate students in psychology and mental health professions. Our study reports the coefficient alpha of total score was 0.88 , Subscale 1: Self Deceptive Enhancement was 0.73, and Subscale 2: Impression Management was 0.86.

\section{Data Analysis Strategy}

Sample size was estimated to be $N=86$ (at $90 \%$ power), adequate for anticipated effect size on the basis of previously published literature (46). A sample of $N=139$ was recruited in this study, which also appears to be appropriate according to Cohen's guideline which suggests $N=97$ is adequate for medium effect size (47). Reliability analyses were also conducted to assess internal consistency of each measure and to ensure their reliability within this novel sample. Descriptive statistics were used to summarise participants' demographic characteristics and the primary dependent variables. Kolmogorov-Smirnov test and Shapiro-Wilk test were conducted to check the normality of the data. One-way ANOVA and Kruskal-Wallis test were performed to identify the between-group (White and non-White practitioners) differences of the perceptions of cultural competence, therapeutic alliance, and racial and ethnic blindness. A correlation analysis was conducted to determine the effect (if any) of participants' gender or age on cultural competence and therapeutic alliance ( $\mathrm{MCl}$ total score). These analyses addressed research questions 1 and 2.

A hierarchical multiple regression analysis was performed to predict practitioner cultural competence and therapeutic alliance (MCl total score). In the first step, social desirability (measured by BIDR subscales) was entered. In the second step, participants' age, ethnicity (for the two groups-White and non-White[1]-entered with dummy codes), and participants' speaking a language other than English were entered. In the third step, cultural competency variables including the number of cultural competence-related workshops, conferences or training sessions attended since beginning practicing mental health care, number of non-White clients[2] seen a week, and whether their formal training prepared them to work with non-White clients were entered. In the fourth step, racial and ethnic blindness attitudes (measured by CoBRAS subscales) were entered. This analysis addressed research questions 3 and 4 . 
[1] Participants were asked to select any and all relevant ethnic identifiers including Asian, Pacific Islander, African, Latin American, Western European, Eastern European, Aboriginal and/or Torres Strait Islander, Indigenous Canadian and/or American, Middle Eastern, Mediterranean and Caucasian. Those who chose Caucasian and/or Western European were categorised as White for the purposes of analysis in line with our previous research in which participants of Western European descent self-identified as White.

[2] To ensure conceptual clarity survey participants were presented with the definition of non-White people indicated in the Background section of this paper.

\section{Results}

Table 1 summarises the demographic, professional, and cultural competency related characteristics of the participants. The mean age of the participants was $37.3(S D=11.3)$ years, with majority being female $(89.2 \%)$. Most of the participants were White (64.7\%), and an Australian citizen (91.4\%). Most participants had completed a postgraduate degree (80.6\%) and had completed their highest level of academic qualification within last five years (59.7\%). All participants received their academic qualifications from Commonwealth countries, and the majority did not speak a language other than English (66.2\%). Of the 139 participants, $76.7 \%$ were psychologists with varied duration working in mental health and types of practice. In terms of cultural competency related characteristics, most participants (93.5\%) were seeing at least one non-White client per week, $82 \%$ of the participants had attended cultural competence-related workshops, conferences, or training sessions since the beginning of their mental health care practice, and over half of the participants (51.5\%) agreed that their qualifying mental health training sufficiently prepared them to provide culturally competent services for non-White clients. 
Variable

\section{Demographic characteristics}

Age (in years)

\section{Gender}

Female

Male

Other

\section{Ethnicity}

Asian

Middle Eastern

White

Australian Residency Status

Australian citizen 127

Australian permanent resident

Student visa holder

\section{Professional (cultural competency and other work related) characteristics}

Highest level of education

Completed postgraduate degree

Completed university degree

Not completed degree at university

Completed high school diploma or equivalent

\section{Year of obtaining qualification}

Within last 5 years (since 2016)

Participants speaks another language in addition to English 


\begin{tabular}{|c|c|}
\hline Variable & $\begin{array}{l}\mathrm{n}(\%) \text { or } \\
\text { Mean } \\
\text { (SD) }\end{array}$ \\
\hline No & $\begin{array}{l}92 \\
(66.2 \%)\end{array}$ \\
\hline \multicolumn{2}{|l|}{ Occupational role } \\
\hline Clinical psychologist & 58 (41.7\%) \\
\hline Psychologist (general) & $\begin{array}{l}36 \\
(25.6 \%)\end{array}$ \\
\hline Psychology trainee (provisional) & $13(9.4 \%)$ \\
\hline Social worker (or trainee) & $6(4.3 \%)$ \\
\hline Counsellor (or trainee) & $7(2.9 \%)$ \\
\hline $\begin{array}{l}\text { Other (Youth/ Community worker, Health Promotion Officer, Medical student, Psychotherapist/or trainee, Pharmacist, Allied health } \\
\text { managers, Occupational therapist, clinical psychologist registrar, Nurse practitioner and Psychology student) }\end{array}$ & $\begin{array}{l}19 \\
(13.7 \%)\end{array}$ \\
\hline \multicolumn{2}{|l|}{ Years working in mental health } \\
\hline $0-1$ years & $\begin{array}{l}19 \\
(13.7 \%)\end{array}$ \\
\hline $2-5$ years & $\begin{array}{l}52 \\
(37.4 \%)\end{array}$ \\
\hline $6-10$ years & $27(19.4 \%)$ \\
\hline $11-14$ years & $12(8.6 \%)$ \\
\hline$\geq 15$ years & $\begin{array}{l}28 \\
(20.1 \%)\end{array}$ \\
\hline \multicolumn{2}{|l|}{ Type of service } \\
\hline Private practice & $\begin{array}{l}59 \\
(42.4 \%)\end{array}$ \\
\hline Public practice & $\begin{array}{l}48 \\
(34.5 \%)\end{array}$ \\
\hline Both private and public practice & $\begin{array}{l}21 \\
(15.1 \%)\end{array}$ \\
\hline Other (none, NGO, disability services, project consulting, research, community clinic) & $5(3.6 \%)$ \\
\hline Both private and other practice & $3(2.2 \%)$ \\
\hline \multicolumn{2}{|l|}{ Cultural competency experience variable } \\
\hline \multicolumn{2}{|l|}{ Number of non-White clients per week } \\
\hline None & $9(6.5 \%)$ \\
\hline $1-3$ & $\begin{array}{l}59 \\
(42.4 \%)\end{array}$ \\
\hline 4-6 & $\begin{array}{l}39 \\
(28.1 \%)\end{array}$ \\
\hline 7-9 & $\begin{array}{l}16 \\
(11.5 \%)\end{array}$ \\
\hline$\geq 10$ & $\begin{array}{l}16 \\
(11.5 \%)\end{array}$ \\
\hline \multicolumn{2}{|l|}{ Engagement in cultural competence-related workshops, conferences or training since beginning practicing mental health care } \\
\hline None & $\begin{array}{l}25 \\
(18.0 \%)\end{array}$ \\
\hline $1-3$ & $\begin{array}{l}75 \\
(54.0 \%)\end{array}$ \\
\hline 4-6 & $\begin{array}{l}30 \\
(21.6 \%)\end{array}$ \\
\hline
\end{tabular}




\begin{tabular}{|lc|}
\hline Variable & $\begin{array}{c}n(\%) \text { or } \\
\text { Mean } \\
\text { (SD) }\end{array}$ \\
\hline $7-9$ & $3(2.2 \%)$ \\
$\geq 10$ & $6(4.3 \%)$ \\
\hline Did your professional mental health training sufficiently prepare you to provide culturally competent services for non-White clients \\
\hline Agree & 71 \\
& $(51.1 \%)$ \\
\hline Neutral & 18 \\
\hline Disagree & $(12.9 \%)$ \\
\hline
\end{tabular}

To examine whether the dependent variables (cultural competence and therapeutic alliance) varied as a function of participants' gender and age, we conducted an analysis of variance (ANOVA) of gender and a correlation analysis of age with the dependent variables. The ANOVA results revealed no significant main effects for participants' gender on $\mathrm{MCl}$ total score, $F(2,139)=0.863, p=0.424$. A correlation analysis showed that age was weakly but statistically significantly correlated with the total score of $\mathrm{MCl}(r=0.183, p=0.032)$ and thus was considered a predictor variable in the final analysis.

\section{Differences In Desirable Responding Across White And Non-white Practitioners}

The average total BIDR score of all participants was $M=10.4(S D=6.8)$ (Table 2). The total score was not statistically different across the two groups despite the non-White group having a higher score than the White group $(M=11.8, S D=7.2 \mathrm{vs}$. $M=9.6, S D=6.3, p=0.094)$. This finding suggests that the groups did not differ in terms of desirable responding.

\section{Differences in Cultural Competence and Therapeutic Alliance across White and non-White Practitioners}

The average total $\mathrm{MCl}$ score of all participants was $M=122.9(S D=14.0)$ (Table 2). The average scores for Subscale 1: Multicultural Counselling Skills, Subscale 2: Multicultural Awareness, Subscale 3: Multicultural Counselling Relationship, and Subscale 4: Multicultural Counselling Knowledge were $M=37.1(S D=5.0), M=27.5(S D=5.0), M=27.5(S D=5.0)$, and $M=33.7(S D=4.8)$, respectively. The total MCl score was higher in the nonWhite group compared to the White group, but the difference was not statistically significant $(M=125.5, S D=14.6 \mathrm{vs}$. $M=121.5, S D=13.6, p=0.069)$. A similar trend was observed for Subscale 4: Multicultural Counselling Knowledge $(M=33.9, S D=5.4$ vs. $M=33.7, S D=4.5, p=0.433)$. While an inverse trend was observed for Subscale 1: Multicultural Counselling Skills $(M=36.7, S D=5.0$ vs. $M=37.3, S D=5.0, p=0.554)$, the differences between the non-White and White groups were not statically significant. However, the scores for Subscale 2: Multicultural Awareness $(M=29.5, S D=$ 5.0 vs. $M=26.4, S D=4.6, p<0.001)$ and Subscale 3 : Multicultural Counselling Relationship $(M=25.4, S D=3.5$ vs. $M=24.2, S D=3.3, p=0.049)$ were significantly higher in the non-White group compared to the White group.

\section{Difference of Color-Blind Racial Attitudes Scale (CoBRAS) across White and non-White Practitioners}

The average total CoBRAS score of all participants was $M=43.8(S D=13.6)$ (Table 2). The scores for Factor 1: Unawareness of Racial Privilege, Factor 2: Unawareness of Institutional Discrimination, and Factor 3: Unawareness of Blatant Racism Issues were $M=18.8(S D=6.4), M=14.4(S D=$ 5.3), and $M=10.6(S D=.3)$, respectively. The total CoBRAS score was significantly higher in the non-White group than the White group $(M=48.0, S D=$ 13.0 vs. $M=41.5, S D=13.6, p=0.007)$. A similar trend was observed for Factor 1 : Unawareness of Racial Privilege $(M=20.9, S D=6.4$ vs. $M=17.6, S D$ $=6.2, p=0.003)$ and Factor 3: Unawareness of Blatant Racism Issues $(M=11.9, S D=4.6$ vs. $M=10.0, S D=4.0, p=0.013)$. The $s c o r e$ for Factor 2: Unawareness of Institutional Discrimination was also higher in the non- White group than the White group $(M=11.9, S D=4.6$ vs. $M=10.0, S D=4.0, p$ = 0.059), however, the difference was not statistically significant. 
Table 2

Differences between White and non-White practitioners' cultural competence and therapeutic alliance, desirable responding, and racial and ethnic blindness.

\begin{tabular}{|c|c|c|c|c|}
\hline $\begin{array}{l}\text { Scores/Variable } \\
\text { Mean (SD) }\end{array}$ & All participants $(n=139)$ & $\begin{array}{l}\text { White } \\
(n=90)\end{array}$ & Non-White $(n=49)$ & p-value \\
\hline Age & $37.3(11.3)$ & $38.5(11.6)$ & $34.7(10.2)$ & $0.077 *$ \\
\hline \multicolumn{5}{|l|}{ Multicultural Counselling Inventory (MCl) } \\
\hline Composite score (MCI Total) & $122.9(14.0)$ & $121.5(13.6)$ & $125.5(14.6)$ & 0.069 \\
\hline Subscale 1: Multicultural Counselling Skills & $37.1(5.0)$ & $37.3(5.0)$ & $36.7(5.0)$ & 0.554 \\
\hline Subscale 2: Multicultural Awareness & $27.5(5.0)$ & $26.4(4.6)$ & $29.5(5.0)$ & $<0.001^{*}$ \\
\hline Subscale 3: Multicultural Counselling Relationship & $27.5(5.0)$ & $24.2(3.3)$ & $25.4(3.5)$ & $0.049 *$ \\
\hline Subscale 4: Multicultural Counselling Knowledge & $33.7(4.8)$ & $33.7(4.5)$ & $33.9(5.4)$ & 0.433 \\
\hline \multicolumn{5}{|l|}{ Balanced Inventory of Desirable Responding (BIDR) } \\
\hline Composite score (BIDR Total) & $10.4(6.8)$ & $9.6(6.3)$ & $11.8(7.2)$ & 0.094 \\
\hline Subscale 1: Self Deceptive Enhancement (SDE) & $4.2(3.1)$ & $3.9(2.9)$ & $4.8(3.2)$ & 0.135 \\
\hline Subscale 2: Impression Management (IM) & $6.2(4.5)$ & $5.7(4.3)$ & $7.0(4.8)$ & 0.132 \\
\hline \multicolumn{5}{|l|}{ Color-Blind Racial Attitudes Scale (CoBRAS) } \\
\hline Composite score (CoBRAS Total) & $43.8(13.6)$ & $41.5(13.6)$ & $48.0(13.0)$ & $0.007^{\star}$ \\
\hline Factor 1 (URP-Unawareness of Racial Privilege) & $18.8(6.4)$ & $17.6(6.2)$ & $20.9(6.4)$ & $0.003^{*}$ \\
\hline Factor 2 (UID-Unawareness of Institutional Discrimination) & $14.4(5.3)$ & $13.9(5.5)$ & $15.4(4.9)$ & 0.059 \\
\hline Factor 3 (UBRI-Unawareness of Blatant Racism Issues) & $10.6(4.3)$ & $10.0(4.0)$ & $11.9(4.6)$ & $0.013^{*}$ \\
\hline
\end{tabular}

\section{Predictors Of Cultural Competence And Therapeutic Alliance}

Table 3 summarises the variables predicting participants' cultural competence and therapeutic alliance. Self-deceptive enhancement (SDE: Subscale 1 of BIDR), the age of participants, attendance of cultural competence-related workshops, conferences, or training sessions since the beginning of mental health care practice, and Unawareness of Blatant Racism Issues (UBRI: Factor 3 of CoBRAS) were observed to contribute significant variance to multicultural competence. The total proportion of variance for the dependent variable, which is explained by the independent variables in the model at Step 4, was calculated as total $R^{2}=0.374$. 
Table 3

Hierarchical multiple regression analysis predicting cultural competence and therapeutic alliance.

\begin{tabular}{|c|c|c|c|c|c|c|c|c|}
\hline Variable & $B$ & $S E B$ & $\beta$ & $\mathrm{t}$ & $R^{2}$ & $\Delta R^{2}$ & $\Delta F$ & $d f$ \\
\hline Step 1 & & & & & 0.141 & 0.141 & $10.706^{\star \star \star}$ & $(2,130)$ \\
\hline BIDR Subscale 1: Self Deceptive Enhancement (SDE) & 1.378 & 0.433 & 0.306 & $3.183^{\star \star}$ & & & & \\
\hline BIDR Subscale 2: Impression Management (IM) & 0.346 & 0.302 & 0.110 & 1.148 & & & & \\
\hline Step 2 & & & & & 0.207 & 0.065 & $3.485^{\star}$ & $(3,127)$ \\
\hline Age & 0.299 & 0.101 & 0.239 & $2.968 * \star$ & & & & \\
\hline Ethnicity (being White) & 1.890 & 2.934 & 0.066 & 0.644 & & & & \\
\hline Participants speaks another language other than English & -2.742 & 3.031 & -0.095 & -0.905 & & & & \\
\hline Step 3 & & & & & 0.278 & 0.072 & $4.102 * \star$ & $(3,124)$ \\
\hline Number of non-White clients per week & 1.805 & 1.001 & 0.143 & 1.804 & & & & \\
\hline $\begin{array}{l}\text { Perception of preparedness to provide culturally competent } \\
\text { services following formative training }\end{array}$ & -0.695 & 1.006 & -0.054 & -0.691 & & & & \\
\hline $\begin{array}{l}\text { Number of cultural competence-related continuing professional } \\
\text { development }\end{array}$ & 3.350 & 1.301 & 0.221 & $2.574^{\star}$ & & & & \\
\hline Step 4 & & & & & 0.374 & 0.095 & $6.142^{\star \star \star}$ & $(3,121)$ \\
\hline CoBRAS Factor1 (URP-Unawareness of Racial Privilege) & 0.117 & 0.211 & 0.054 & 0.557 & & & & \\
\hline $\begin{array}{l}\text { CoBRAS Factor2 (UID Unawareness of Institutional } \\
\text { Discrimination) }\end{array}$ & 0.413 & 0.253 & 0.158 & 1.629 & & & & \\
\hline CoBRAS Factor3 (UBRI Unawareness of Blatant Racism Issues) & -1.323 & 0.329 & -0.410 & -4.023 & & & & \\
\hline
\end{tabular}

Self-deceptive enhancement was observed to contribute to the variance of cultural competence and therapeutic alliance, $F(2,130)$ change $=10.706, p<$ $0.001, R^{2}=0.141$, and $R^{2}$ change $=0.141$, but not Impression Management. In Step 2, age was the only variable which contributed to the variation in cultural competence and therapeutic alliance in addition to Self-Deceptive Enhancement from Step $1, F(3,127)$ change $=3.485, p=0.018, R^{2}=0.207$, and $R^{2}$ change $=0.065$. The ethnicity of the participants (White and non-White) and the ability of the participants to speak a language other than English did not contribute to variance in cultural competence and therapeutic alliance. Similarly, in Step 3, variables related to practitioners' cultural competence experience were added to social desirability (BIDR subscales), age, ethnicity, ability to speak another language other than English. Cultural competence experience variables included: attendance at cultural competence-related workshops, conferences, or training sessions; number of nonWhite clients seen per week; and perceived preparedness to work with non-White clients following qualifying mental health training.

Step 3 yielded additional significant variance in cultural competence and therapeutic alliance, $F(3,124)$ change $=4.102, p=0.008, R^{2}=0.278$, and $R^{2}$ change $=0.072$. However, the number of non-White clients per week and the belief that professional mental health training sufficiently prepared them to provide culturally competent services for non-White clients did not contribute any significant effect on cultural competence and therapeutic alliance. In the final step (Step 4), the three subscales of CoBRAS were added in addition to all the variables in the previous steps. The analysis revealed that Unawareness of Blatant Racism Issues, together with the variables added in Steps 1 to 3, contributed to additional significant variance in cultural competence and therapeutic alliance with a large effect size, $F(3,121)$ change $=6.142, p<0.001, R^{2}=0.374$, and $R^{2}$ change $=0.095$.

\section{Discussion}

The purpose of this study was to identify the factors that influence Australian mental health practitioners' cultural competence and therapeutic alliance. The findings indicate that practitioners in this study valued cultural competence training given their high level of engagement in this type of continuing professional development. This may be in response to the fact that the vast majority engaged with at least one non-White client a week and wanted to maintain and/or improve their ability to provide culturally competent services to their non-White clients (24, 39).

Participants in the current study reported a similar level of cultural competence and therapeutic alliance to those reported in previous studies. The $\mathrm{MCl}$ total score $(M=122.9, S D=14.0)$ for the sample is approximately equivalent to data reported by Bellini et al. $(46)(M=125.1, S D=14.32)$ and $\mathrm{Green}$ et al. (48) $(M=126.71)$ for rehabilitation counselors $(n=372)$ and social workers $(n=344)$, respectively. The findings also indicate that non-White practitioners had higher levels of cultural awareness and better therapeutic alliances with non-White people compared to White practitioners. This finding is consistent with research from other countries where non-White health practitioners demonstrate higher levels of cultural competence (44, 45). Extant literature indicates that non-White people have personal experiences related to the various challenges that Whiteness presents in their own 
lives, resulting in a high level of awareness of Whiteness and its impact on non-White people $(30,49-51)$. Consequently, non-White people are more likely to build a more robust connection with non-White clients due to their increased ability to be empathetic to their clients' experiences particularly with regards to discrimination-related distress $(49,52,53)$.

In line with international samples of mental health practitioners, the current sample demonstrated low to moderate levels of colour-blind racial and ethnic attitudes with average CoBRAS total scores of $M=43.8(S D=13.6)$. For instance, Neville et al. (41) reported that their sample of 152 American mental health workers and trainees "held low to moderate levels of color-blind racial beliefs" (p. 483) with mean CoBRAS score of $M=48.59(S D=$ 12.79). Interestingly, non-White practitioners in the current study were more likely to be in denial about racial privilege and the pervasiveness of racial/ethnic issues in Australia compared to their White counterparts. This may be because many White people from low socioeconomic backgrounds experience significant systemic disadvantages as a result of the pressures of Whiteness $(11,12,54)$. Non-White practitioners working with a diversity of clients may therefore see parallels between White and non-White clients from low socioeconomic backgrounds and be less likely to attribute disadvantage to experiences of racial/ethnic discrimination (15). Another plausible explanation may be that non-White practitioners may be responding according to perceptions of their own privileges and the advantages they experience given their high levels of education, career capital and social positioning. Additionally, non-White practitioners may not want to buy-in to the idea that Australia suffers from pervasive and insurmountable institutional racism as this may hinder their own wellbeing and ability to encourage their non-White clients towards a fulfilling life.

The results of the hierarchical multiple regression indicate that highly favourable perceptions of self and protection of self-esteem (BIDR Subscale 1: Self Deceptive Enhancement SDE) was positively associated with practitioner cultural competence and therapeutic alliance (MCI total score). As such, an increase in the levels of self-deceptive enhancement, or an honest but overly positive responding, was found to be linked with greater multicultural competence. This may be because practitioners who perceive themselves more positively may have a higher sense of confidence in their abilities and therefore rate themselves as more culturally competent (39). It could also be that participants protected their self-esteem due to the fear of being perceived as a culturally incompetent practitioner. This fear may be so strong, that practitioners may be inclined to even engage in self-deception to avoid it. These interpretations align with other literature which indicates the identity threat experienced by mental health care providers when confronted with information about Whiteness and their possible role in its perpetuation $(45,55-57)$.

The relationship between social desirability, cultural competence, and therapeutic alliance was unexpected given previous research which found no significant association between these variables. While some researchers (37) proport that social desirability is an important issue in relation to selfreport in cultural competence, others have not found any relationship between these variables $(41,45)$. Following Chao (2013), the BIDR was included in this study. However, unlike Chao (2013) or Neville (2006) who found no relationship between these variables, the current study found a significant relationship between the self-deceptive enhancement subscale and higher $\mathrm{MCl}$ scores.

The hierarchical analysis also showed that participant's age as well as the number of cultural competence-related workshops, conferences, or training sessions attended since the beginning of mental health care practice were found to be positively associated with cultural competence and therapeutic alliance. This finding suggests that cultural competence and therapeutic alliance grows with clinical experience, regular engagement in training and maturity as a practitioner.

The hierarchical multiple regression also revealed that higher levels of unawareness of general and pervasive racial/ethnic discrimination (CoBRAS Factor 3: Unawareness of Blatant Racism Issues (UBRI) are negatively associated with cultural competence and therapeutic alliance (total MCI score). This finding mirrors those in other studies $(41,58,59)$ and highlights that addressing race and racism is central to cultural competence training. Notably, the lack of training on race and racism may be why $48.9 \%$ of the sample were either neutral or disagreed that their qualifying training had prepared them to work with non-White people.

In summary, the study results demonstrate that higher cultural competence and therapeutic alliance are associated with being non-White, practitioner's age, greater attendance of cultural competence-related trainings and increased awareness of general and pervasive racial and/or ethnic discrimination. Practitioners with higher cultural competence and therapeutic alliance are likely to perceive of themselves more favourably than those with lower levels of competence.

\section{Implications And Recommendations For Training And Practice}

The findings of this study reinforce the need for continued engagement in cultural competence training across the full trajectory of a practitioner's mental health career. The current study reiterates the importance of continuously addressing Whiteness by explicitly discussing White supremacy, privilege and power (for example) in Western mental health care settings and clearly identifying their impact on all people, not only those identifying as non-White (60-62). This reflects a growing national focus on key components of cultural competence training and implementation, namely multicultural awareness, and relationships. For instance, the Australian Heath Practitioner Regulation Agency (AHPRA) encourages health practitioners not only to learn about why difference is a significant factor in therapeutic relationships but also how to engage with diverse clients in culturally competent ways (63). While their current guidelines are focused on Indigenous Australians, many of the principles apply to other non-White groups. Given the lack of cultural competency guidelines from AHPRA relevant to the many other non-White groups in Australia, the development of such training and best-practice is needed to ensure mental health practitioner's preparedness to work with diverse populations. This recommendation is reinforced by the fact that cultural competence, a precursor to an effective therapeutic alliance, is an integral part of all 15 health professions regulated by AHPRA and their professional codes of conduct. 
Training should, however, be focused on addressing the particular needs of practitioners at various levels of experience and consider practitioner race and ethnicity. Pragmatically, practitioners could, for example, begin by completing demographic items as well as questions related to their existing counselling competence and therapeutic alliance skills. Their responses would then determine allocation to training relevant to their age, racial/ethnic background as well as their professional experiences and expertise. For instance, younger, less experienced, White practitioners could engage in training that included discussions about Whiteness and anti-racism in mental health practice and services. Additionally, those practitioners with higher levels of cultural competence and therapeutic alliance can work on developing, implementing, or enhancing therapeutically safe mental health practises and those with lower levels can be introduced to the concepts and implications for their practice.

Aligned with the study findings, mental health care practices should actively engage with non-White populations to increase opportunities for cultural encounters between mental health practitioners and non-White clients $(64,65)$. This can be done by offering home visits or providing services within community centres. Such engagement activities can also serve to decrease ethnic and racial colour-blindness amongst practitioners and offer opportunities for clients to develop effective therapeutic alliance with mental health care providers (56). Given that many mental health practitioners, particularly psychologists, work in one-on-one settings engagement with their professional networks, case conferencing and clinical practice supervision can assist in increasing their awareness of general and pervasive racial and/or ethnic discrimination experienced by their clients (66-68). Such forums would be especially effective where topics of race and Whiteness are directly addressed so that practitioners can be regularly challenged by their peers to reduce their racial and ethnic blindness and minimise the harm of practitioner ignorance on non-White clients.

\section{Limitations And Future Research}

There are limitations to this study. First, the majority (76.7\%) of the sample were psychologists which may limit the generalisability of the results to other mental health practitioners given that psychologists often work one-to-one with mental health clients. Further research including a more diverse sample of mental health practitioners would provide a more robust representation of cultural competence and therapeutic alliance within the mental health sector. In addition, because of the limited number of non-White practitioners from diverse groups they were combined into a single group. Consequently, the results cannot be generalised to any particular group of non-White practitioners (e.g., Asian Australians, African Australians, Indigenous Australians). Research including a more diverse sample of mental health professionals may provide more information about the relationships between cultural competence, therapeutic alliance and other variables like sex, age, duration of practice, and ethnicity. With a more diverse sample between groups difference can be explored more rigorously.

Second, the collected data drew on mental health practitioners' self-report. It is well documented that self-report may not reflect actual levels of cultural competence (69-71). Given that this study found a positive correlation between self-deceptive enhancement and cultural competence, additional methods for determining practitioner cultural competence and therapeutic alliance are needed. This may include a comparison between clients' perceptions of their therapist's cultural competence versus their practitioners' self-perceptions (72-74). Further, observations and/or analysis of recordings of mental health sessions can be used to determine the provider's cultural competence. While these recommendations present their own methodological limitations, they may be more in line with a culturally competent approach (75). Self-report may also contribute to the surprising relationships found between socially desirable responding and cultural competence and therapeutic alliance. As such, future studies with larger and more diverse samples should examine the association between social desirability and cultural competence and therapeutic alliance.

\section{Conclusion}

This is the first Australian study to explore the complex relationships among mental health care practitioners' sociodemographic variables, cultural competence, therapeutic alliance, multicultural training, colour-blind racial attitudes, and social desirability. Additionally, it is one the few studies to use a series of regressions to analyse moderating variables and their effect on cultural competence and therapeutic alliance. The study sheds light on the attributes of mental health practitioners in Australia working with diverse clients while also navigating their own diversity and difference. The findings highlight that the current one-size-fits-all and skills-development approach to cultural competence training ignores the significant role that practitioner diversity and differences play in the therapeutic alliance. The recommendations from this study can inform clinical educators and supervisors about the importance of continuing professional development relevant to practitioners' age, professional experience, and ethnic/racial background.

\section{Abbreviations}

MCl: Multicultural Counselling Inventory

CoBRAS: Color-blind Racial Attitudes Scale

BIDR: Balanced Inventory for Desirable Responding

AHPRA: Australian Health Practitioner Regulation Agency

\section{Declarations}

\section{Ethics approval and consent to participate}


The study was approved by the Human Research Ethics Committee (Approval Number 2017/105) at the University of Wollongong. Before completing the survey, participants were asked to tick a box indicating that they had read the Participant Information Sheet and consented to participate. Participants were advised that only those who completed the survey in full would be provided with a $\$ 25$ electronic gift voucher which could be redeemed at an Australian grocery store or its subsidiaries.

\section{Consent for publication}

Not applicable.

\section{Availability of data and materials}

Upon request, all relevant raw data will be freely available to any scientist wishing to use them for non-commercial purposes and without breaching participant confidentiality.

\section{Competing interests}

The authors declare that they have no competing interests.

\section{Funding}

This work was supported by an Australian Government Research Training Program Scholarship which had no role in the design of the study or data collection, analysis, interpretation of the data or in writing this manuscript.

\section{Authors' contributions}

Author TD conceptualised the project with the supervision and guidance of authors PC, KO and CM. Author AO engaged in the recruitment, data collection and cleaning of the data with author TD. Author RC engaged in the data cleaning and data analysis with author TD. Author TD drafted the manuscript and received assistance in quantitative results reporting from author RC. TD received conceptual and editorial feedback from authors PC, $\mathrm{KO}$ and $\mathrm{CM}$. Author $\mathrm{AO}$ assisted in the editorial review and presentation of the article for publication. All authors have reviewed this article and consent to its publication.

\section{Acknowledgements}

The authors would like to acknowledge the time and perspectives of the participants who made time for this research despite their busy schedules and heavy client loads.

\section{References}

1. Australian Bureau of Statistics. Migration, Australia Canberra: Australian Goverment; 2021 [Available from: https://www.abs.gov.au/statistics/people/population/migration-australia/2019-20.

2. Australian Bureau of Statistics. Census Data Summary: Australian Government; 2016 [Available from: https://www.abs.gov.au/ausstats/abs@.nsf/Lookup/by\%20Subject/2071.0 2016 Main\%20Features Snapshot\%20of\%20Australia,\%202016 2.

3. The Diversity Style Guide. White, white 2019 [Available from: https://www.diversitystyleguide.com/glossary/white-white/.

4. Spangaro J, Herring S, Koziol-Mclain J, Rutherford A, Frail M-A, Zwi AB. 'They aren't really black fellas but they are easy to talk to': Factors which influence Australian Aboriginal women's decision to disclose intimate partner violence during pregnancy. Midwifery. 2016;41:79-88.

5. Beagan BL, Chacala A. Culture and diversity among occupational therapists in Ireland: When the therapist is the 'diverse' one. Br $\mathrm{J}$ Occup Ther. 2012;75(3):144-51.

6. Du Bois WEB. Darkwater: Voices from within the veil New York: Schocken; 1920/1969.

7. Du Bois W. Darkwater: The Givens Collection: Simon and Schuster; 2010.

8. DiAngelo R. White fragility: Why it's so hard for white people to talk about racism. Boston, USA: Beacon Press; 2018.

9. Fanon F. Black skin, white masks. New York: Grove Press; 1967.

10. Sue DW. The invisible Whiteness of being: Whiteness, White supremacy, White privilege, and racism. In: Constantine MG, Sue DW, editors. Addressing racism: Facilitating cultural competence in mental health and educational settings. Hoboken, NJ, US: John Wiley \& Sons Inc; 2006. p. $15-30$. 
11. Dune T, Caputi P, Walker BM, Olcon K, MacPhail C, Firdaus R, et al. Construing Non-white and White Clients: Mental Health Practitioners' Superordinate Constructs Related to Whiteness and Non-Whiteness in Australia. Journal of Constructivist Psychology. 2021.

12. Dune T, Caputi P, Walker BM, Olcon K, MacPhail C, Firdaus R, et al. Australian mental health care practitioners' construing of non-White and White people: Implications for cultural competence and therapeutic alliance. BMC psychology. 2021;9(1):1-17.

13. Lewis AE. What group? Studying Whites and Whiteness in the era of color-blindness. Sociological theory. 2004;22(4):623-46.

14. Guess TJ. The social construction of whiteness: Racism by intent, racism by consequence. Critical Sociology. 2006;32(4):649-73.

15. Olson R, Bidewell J, Dune T, Lessey N. Developing Cultural Competence through Self-Reflection in Interprofessional Education in Australia. Journal of Interprofessional Care. 2016;30(3):347-54.

16. Australian Institute of Health and Welfare. Mental health services in Australia: Australian Government; 2020 [Available from: https://www.aihw.gov.au/reports/mental-health-services/mental-health-services-in-australia/report-contents/summary-of-mental-health-servicesin-australia/prevalence-impact-and-burden

17. Australian Institute of Health and Welfare. Australian burden of disease study: impact and causes of illness and death in Australia 2015. Australian Burden of Disease Study series no 19 Cat no BOD 22. Canberra: Australian Government; 2019.

18. Australian Institute of Health and Welfare. Mental health services in Australia: Australian Government; 2021 [Available from: https://www.aihw.gov.au/reports/mental-health-services/mental-health-services-in-australia/report-contents/expenditure-on-mental-health-relatedservices.

19. Malat J, Clark-Hitt R, Burgess DJ, Friedemann-Sanchez G, Van Ryn M. White doctors and nurses on racial inequality in health care in the USA: whiteness and colour-blind racial ideology. Ethnic and racial studies. 2010;33(8):1431-50.

20. Dune T, Caputi P, Walker B. A systematic review of mental health care workers' constructions about culturally and linguistically diverse people. PLoS One. 2018;13(7):1-20.

21. Gomersall JS, Gibson O, Dwyer J, O'Donnell K, Stephenson M, Carter D, et al. What Indigenous Australian clients value about primary health care: a systematic review of qualitative evidence. Australian New Zealand Journal of Public Health. 2017;41(4):417-23.

22. Maul CA. Working with culturally and linguistically diverse students and their families: Perceptions and practices of school speech-language therapists in the United States. International Journal of Language \& Communication Disorders. 2015;50(6):750-62.

23. Horevitz E, Lawson J, Chow JCC. Examining cultural competence in health care: Implications for social workers. Health Soc Work. 2013;38(3):135-45.

24. Bitney C. Broaching racial difference between African American clients and White counselors: Racial identity attitudes and therapy process [Ph.D.]. Ann Arbor: New School University; 2012.

25. Anderson W. The cultivation of whiteness: Science, health and racial destiny in Australia. New York, USA: Basic Books; 2003.

26. Kirmayer LJ. Rethinking cultural competence. Transcultural Psychiatry. 2012(2):149-64.

27. National Health and Medical Research Council. Cultural Competency in health: A guide for policy, partnerships and participation. Canberra, Australia: National Health and Medical Research Council; 2014.

28. Garran AM. Cultural competence, racial identity, and ethnocultural empathy in therapeutic engagement with at risk, urban adolescents of color: Smith College School for Social Work, Northampton, Mass.; 2008.

29. Bahamonde MM. Examining cultural competence in school psychology practice. Florida: University of Florida; 2008.

30. Chen C. Cultural competence of school psychologists working with Asian American youth: Enhancing accessibility of school psychology services. New Jersey: Rutgers University; 2017.

31. Martin DJ, Garske JP, Davis MK. Relation of the therapeutic alliance with outcome and other variables: A meta-analytic review. Journal of consulting and clinical psychology. 2000;68(3):438.

32. Zugai JS, Stein-Parbury J, Roche M. Therapeutic alliance in mental health nursing: an evolutionary concept analysis. Issues in Mental Health Nursing. 2015;36(4):249-57.

33. Ojedokun O, Idemudia ES. Psycho-socio-emotional well-being of workers in a high-stress occupation: are men and women really so different? Gender and Behaviour. 2014;12(3):5824-38.

34. Freud S. Recommendations to physicians practising psycho-analysis. In: Strachey J, editor. The standard edition of the complete psychological works of Sigmund Freud: The case of schreber, papers on technique and other works. Volume XII (1911-1913). London: The Hogarth Press and the Institute of Psycho-analysis; 1912. p. 109-20.

35. Sánchez-Bahíllo A, Aragón-Alonso A, Sánchez-Bahíllo M, Birtle J. Therapist characteristics that predict the outcome of multipatient psychotherapy: Systematic review of empirical studies. J Psychiatr Res. 2014;53(1):149-56.

36. Sodowsky GR, Taffe RC, Gutkin TB, Wise SL. Development of the Multicultural Counseling Inventory: A self-report measure of multicultural competencies. Journal of Counseling Psychology. 1994;41(2):137.

37. Sodowsky GR. The Multicultural Counseling Inventory: Validity And Applications In Multicultural Training. In: Sodowsky GR, Impara J, editors. Multicultural assessment in counseling and clinical psychology. Lincoln, NE: Buros Institute of Mental Measurement; 1996. 
38. Ottavi TM, Pope-Davis DB, Dings JG. Relationship between White racial identity attitudes and self-reported multicultural counseling competencies. Journal of Counseling Psychology. 1994;41(2):149.

39. Campinha-Bacote J. The process of cultural competence in the delivery of healthcare services: A model of care. Journal of Transcultural Nursing. 2002;13(3):181-4.

40. Escudero V, Friedlander ML, Varela N, Abascal A. Observing the therapeutic alliance in family therapy: associations with participants' perceptions and therapeutic outcomes. Journal of Family Therapy. 2008;30(2):194-214.

41. Neville H, Spanierman L, Doan B-T. Exploring the association between color-blind racial ideology and multicultural counseling competencies. Cultural Diversity and Ethnic Minority Psychology. 2006;12(2):275.

42. Paulhus DL. Balanced inventory of desirable responding: Reference manual for BIDR version 6. Unpublished manuscript, University of British Columbia, Vancouver, Canada. 1994.

43. Paulhus D. Balanced inventory of desirable responding (BIDR). Acceptance and Commitment Therapy Measures Package. 1988;41.

44. Chao R. Counselors' Multicultural Competencies: Race, Training, Ethnic Identity, and Color-Blind Racial Attitudes. In: Walz GR, Bleuer JC, Yep RK, Walz GR, Bleuer JC, Yep RK, editors. Vistas: Compelling perspectives on counseling 2006. Alexandria, VA, US: American Counseling Association; 2006. p. 73-6.

45. Chao RC-L. Race/Ethnicity and Multicultural Competence Among School Counselors: Multicultural Training, Racial/Ethnic Identity, and Color-Blind Racial Attitudes. J Couns Dev. 2013;91(2):140-51.

46. Bellini J. Correlates of multicultural counseling competencies of vocational rehabilitation counselors. Rehabilitation Counseling Bulletin. 2002;45(2):66-75.

47. Cohen J. A power primer. Psychol Bull. 1992;112(1):155-9.

48. Green RG, Kiernan-Stern M, Bailey K, Chambers K, Claridge R, Jones G, et al. The multicultural counseling inventory: A measure for evaluating social work student and practitioner self-perceptions of their multicultural competencies. Journal of Social Work Education. 2005;41(2):191-208.

49. Fretts JM. A phenomenological analysis of the White therapist and American Indian client dyad: Common factors, cultural competence, cultural humility, and microaggressions. Montana: The University of Montana; 2016.

50. Stone TE, Francis L, van der Riet P, Dedkhard S, Junlapeeya P, Orwat E. Awakening to the other: reflections on developing intercultural competence through an undergraduate study tour. Nurs Health Sci. 2014;16(4):521-7.

51. Owen J, Tao KW, Imel ZE, Wampold BE, Rodolfa E. Addressing racial and ethnic microaggressions in therapy. Professional Psychology: Research and Practice. 2014;45(4):283-90.

52. Hook JN, Farrell JE, Davis DE, DeBlaere C, Van Tongeren DR, Utsey SO. Cultural humility and racial microaggressions in counseling. Journal of Counseling Psychology. 2016;63(3):269-77.

53. Hayes JA, Owen J, Bieschke KJ. Therapist differences in symptom change with racial/ethnic minority clients. Psychotherapy. 2015;52(3):308-14.

54. Malat J, Mayorga-Gallo S, Williams DR. The effects of whiteness on the health of whites in the USA. Social Science \& Medicine. 2018;199:148-56.

55. Bentley P, Jovanovic A, Sharma P. Cultural diversity training for UK healthcare professionals: A comprehensive nationwide cross-sectional survey. Clin Med J R Coll Phys Lond. 2008;8(5):493-7.

56. Consoli AJ, Kim BSK, Meyer DM. Counselors' Values Profile: Implications for Counseling Ethnic Minority Clients. Counseling and Values. 2008;52(3):181-97.

57. Dickson GL, Jepsen DA. Multicultural Training Experiences as Predictors of Multicultural Competencies: Students' Perspectives. Counselor Education and Supervision. 2007;47(2):76-95.

58. Estrellado JE. Clinicians' attributions of symptoms to trauma and ethnic minority status based on client presentation [Ph.D.]. Ann Arbor: Alliant International University; 2015.

59. Gushue GV, Constantine MG. Color-blind racial attitudes and white racial identity attitudes in psychology trainees. Professional Psychology: Research and Practice. 2007;38(3):321.

60. Petray TL, Collin R. Your privilege is trending: Confronting whiteness on social media. Social Media and Society. 2017;3(2):2056305117706783.

61. Olson ED. 'Why blame me?' interpreting counselor student resistance to racially themed course content as complicity with white racial hegemony [PhD]. US: University of New Mexico; 2014

62. Mapedzahama V, Rudge T, West S, Perron A, editors. Racial/ised Visibility and Problematised Difference in Australian Workplaces: The Case of Skilled Black African Migrant Nurses. Directions and Intersections: Proceedings of the 2011 Australian Critical Race and Whiteness Studies Association and Indigenous Studies Research Network Joint Conference; 2011.

63. AHPRA. Aboriginal and Torres Strait Islander Health Strategy 2020 [Available from: https://www.ahpra.gov.au/About-AHPRA/Aboriginal-andTorres-Strait-Islander-Health-Strategy.aspx\#statement-of-intent.

64. Arthur N, Januszkowski T. The multicultural counselling competencies of Canadian counsellors. Canadian Journal of Counselling. 2001;35(1):3648.

65. Cross WM, Bloomer MJ. Extending boundaries: clinical communication with culturally and linguistically diverse mental health clients and carers. Int J Ment Health Nurs. 2010;19(4):268-77. 
66. Forsetlund L, Eike MC, Vist GE. Effect of interventions to improve health care services for ethnic minority populations. Nor Epidemiol. 2010;20(1):41-52.

67. Graham-Clay S. Enhancing home-school partnerships: how school psychologists can help. Canadian Journal of School Psychology. 1999;15(1):31-44.

68. Kuo BCH, Arcuri A. Multicultural Therapy Practicum Involving Refugees: Description and Illustration of a Training Model. Counseling Psychologist. 2014;42(7):1021.

69. Constantine MG. Survey of Professional Needs of Division 17's Ethnic and Racial Minority Psychologists. 19951995.

70. Constantine MG. Predictors of satisfaction with counseling: Racial and ethnic minority clients' attitudes toward counseling and ratings of their counselors' general and multicultural counseling competence. Journal of Counseling Psychology. 2002;49(2):255-63.

71. Constantine MG, Gushue GV. School Counselors' Ethnic Tolerance Attitudes and Racism Attitudes as Predictors of Their Multicultural Case Conceptualization of an Immigrant Student. Journal of Counseling \& Development. 2003;81(2):185.

72. Whealin JM, King L, Shore P, Spira JL. Diverse veterans' pre- and post-intervention perceptions of home telemental health for posttraumatic stress disorder delivered via tablet. International Journal of Psychiatry in Medicine. 2017;52(1):3-20.

73. Ekmekci H, Yavuz-muren HM, Emmen RA, Mesman J, van ljzendoorn MH, Yagmurlu B, et al. Professionals' and Mothers' Beliefs About Maternal Sensitivity Across Cultures: Toward Effective Interventions in Multicultural Societies. Journal of Child and Family Studies. 2015;24(5):1295-306.

74. Ibaraki AY, Hall GCN. The Components of Cultural Match in Psychotherapy. Journal of Social and Clinical Psychology. 2014;33(10):936-53.

75. Dune TM, McLeod K, Williams R. Culture, Diversity and Health in Australia: Towards Culturally Safe Health Care: Routledge; 2021. 